\title{
DOSSIE
}

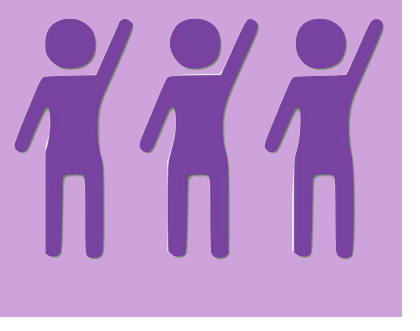

\section{A Violência Psicológica Contra a Mulher}

Reconhecimento e Visibilidade

Gabriela Bothrel EchEvERRIA, Centro Universitário Tiradentes

No Brasil, segundo o Data Senado (2013) cerca de 38\% das mulheres afirmam ter sofrido violência psicológica. Assim, este trabalho tem como objetivo de discutir a compreensão de estudantes do curso de Direito sobre a violência psicológica contra a mulher, analisando de que forma estão se preparando para lidar com tal demanda de trabalho e se há, por parte destes estudantes e futuros profissionais, o reconhecimento da violência psicológica como precedente de outras formas de violência. Utilizamos de um questionário online sobre a percepção dos tipos de violência e noções jurídicas sobre a Lei Maria da Penha, utilizada como arcabouço teórico da discussão. Os resultados apontam que embora a temática venha ganhando importância, uma grande parcela dos estudantes não soube tipificar a violência psicológica. Nota-se que não basta explicar o significado deste tipo de violência, se não houver um aparato jurídico claro e objetivo de como proceder e as quais outros profissionais recorrer. Cabe à psicologia promover ações interdisciplinares fomentando tal discussão e possibilitando a construção de novos espaços de discussão e de construção/efetivação de uma rede integrada de saberes para suporte para as mulheres vítimas de violência, e para discutir a tipificação no âmbito jurídico da violência psicológica.

PALAVRAS-ChAVE: Violência psicológica. Invisibilidade. Lei Maria da Penha. 


\section{Introdução}

A violência é um tema tão abrangente como multifacetado. Historicamente, é caracterizada como um fenômeno social que pode ser analisada pelo viés antropológico, jurídico, sociocultural, psicológico e biológico, ou seja, a violência é multicausal. Dentro desse variado leque explicativo acerca do tema, há a compreensão dele a partir de uma perspectiva de problema de saúde pública, pois ao passo que a violência afeta de forma direta a saúde e o bem-estar individual, consequentemente atinge também a saúde coletiva e gera uma demanda na criação de políticas públicas (SACRAMENTO; REZENDE, 2006) \& (LIMA; BÜCHELE; CLİMACO, 2008).

Rodrigues (2014) pontua que para compreender a violência contra a mulher como uma questão de saúde pública, faz-se necessário entender que os agravos gerados pela intimidação por meio dela acarretam em danos mentais e na sua saúde física. Assim, o medo e as apreensões sentidas pelo corpo desencadeiam em doenças orgânicas, podendo ocasionar inclusive a morte de muitas dessas vítimas. Baseado nos dados da Organização das Nações Unidas (ONU) (2006) e pela Organização Pan-Americana da Saúde (OPAS) (2002), a violência contra a mulher não pode permanecer na esfera individual, entre agressor e vítima, dado seu caráter endêmico. Neste prisma, percebe-se que as sequelas variam desde problemas físicos não graves a outros sexuais, reprodutivos e, em alguns casos, à morte, a exemplo de casos de suicídio. Por isso, esse fenômeno se configura como um ato que, antes de tudo, fere o direito à qualidade de vida, primordial a todo e toda cidadã brasileira.

No país, aproximadamente uma em cada cinco mulheres afirma ter sofrido violência doméstica ou intrafamiliar provocada por um homem e 38\%, violência psicológica (DATA SENADO, 2013). Então, tendo como base o panorama de violência contra a mulher, o foco deste trabalho será a violência psicológica, que como Machado \& Dezanoski (2014) explicam, precede as demais formas de violência e em sua maioria é praticada, cotidianamente, por parceiros e ex-parceiros, deixando marcas invisíveis a olho nu, mas dilacerantes do ponto de vista da saúde emocional.

Com viés qualitativo, esta pesquisa foi realizada através de um questionário online, elaborado pelo site SurveyMonkey, que teve como objeto de análise os estudantes do curso de Direito. Tal questionário foi 
respondido anonimamente e as distinções para filtrar as respostas foram realizadas a partir da Instituição de Ensino Superior do participante, qual período do curso e sexo. Com um formato semi-dirigido, teve perguntas de Escala Likert e múltipla escolha, como também perguntas abertas, para possibilitar respostas discursivas sobre o tema, que variou bastante, englobando desde conhecimentos e noção sobre a violência psicológica contra a mulher até seus aspectos legais e a prática profissional.

Para tanto, a ampliação da discussão sobre esta temática tem como foco diminuir a invisibilidade da violência psicológica, sendo preciso este diálogo dentro da academia para que se possa refletir fora dela, em diversos segmentos sociais.

\section{Violências contra a mulher}

De acordo com a Organização das Nações Unidas (ONU) (2006), a violência contra a mulher existe e persiste por vários países e viola os direitos humanos, além de impedir a igualdade de gênero (MINISTÉRIO DA SAÚDE, 2012). De acordo com a Organização dos Estados Americanos (OEA) (1996) apud Mühlen, Dewes e Strey (2012), a expressão "violência contra a mulher" pode ser contemplada nas mais diversas situações e classificações, como violência física, sexual, psicológica, cometida por parceiro íntimo; além do estupro; abuso sexual de meninas; assédio sexual no trabalho; violência étnica e racial; violência realizada pelo estado por ação ou omissão; mutilação genital; violência e assassinatos ligados ao dote; e estupros em massa nas guerras e conflitos armados.

No panorama brasileiro, aproximadamente uma em cada cinco mulheres afirma ter sofrido violência doméstica ou intrafamiliar provocada por um homem, o que mostra que quantitativamente, a violência física ocorreu em $62 \%$ das mulheres entrevistadas, das quais $39 \%$ sofreram violência moral, $38 \%$ violência psicológica e $12 \%$ violência sexual. De acordo com os registros, quanto menor a escolaridade, maior o número de registros de violência cometidos e dentre as vítimas: 65\% afirmam que sofreram a violência por parte do próprio parceiro/ namorado/marido, $13 \%$ por ex-parceiro/ex-namorado/ex-marido e $11 \%$ por parentes consanguíneos e cunhados (DATA SENADO, 2013). 
De acordo com Campos (2011), existiram estereótipos socialmente atribuídos ao gênero ligando a razão ao masculino e a sensibilidade ao feminino, refletindo na dicotomização de pensamentos e na separação de comportamentos entre os gêneros, sendo esta uma das principais críticas da teoria feminista do direito. Muszkat (2006), inclusive, fez uma colocação muito pertinente quando lembrou que a cultura que reproduz e perpetua as relações hegemônicas de gênero, nas quais práticas de dominação dos homens sobre as mulheres são avalizadas, não se restringe somente ao universo masculino, pois muitas mulheres ainda compartilham destes mesmos códigos e valores contribuindo para sua manutenção e formação de relacionamentos fundamentados nessa dinâmica que possibilita tal complementação ou retroalimentação.

Falar de violência contra a mulher não nos remete somente à situação em que marcas físicas possam referendar o ato em si, embora saibamos que dentro de uma primeira impressão sobre o tema, a violência física e a sexual são as mais proeminentes em expressão e reconhecimento. No entanto, é na psicológica, praticada nos entremeios do cotidiano, que se registra o pontapé inicial para um processo de violência que pode culminar em situações de agravo (MEDRADO; MELLO, 2008). Entrementes, quando se analisa a dimensão psíquica da violência psicológica, percebe-se que a mesma faz parte de um ciclo. Segundo Minayo (2006) apud Ferreira (2010), a violência psicológica está presente em todos os outros tipos e pode ser descrita em quatro fases, sendo elas: 1) Da tensão; 2) Da agressão; 3) Das desculpas; e 4) Da reconciliação - que ocorrem como ciclos sempre se repetindo e prejudicando a saúde mental da figura feminina. Sendo assim, para uma maior apropriação das situações onde a violência psicológica se manifesta e como referencial para este trabalho, adotou-se a concepção de violência psicológica descrita na Lei Maria da Penha em seu artigo $7^{\circ}$, inciso II:

Art. 70 São formas de violência doméstica e familiar contra a mulher, entre outras:

(...)

II- a violência psicológica, entendida como qualquer conduta que lhe cause dano emocional e diminuição da autoestima ou que lhe prejudique e perturbe o pleno desenvolvimento ou que vise degradar ou controlar suas ações, comportamentos, crenças e decisões, mediante ameaça, constrangimento, humilhação, manipulação, isolamento, vigilância constante, perseguição contumaz, insulto, 
chantagem, ridicularização, exploração e limitação do direito de ir e vir ou qualquer outro meio que lhe cause prejuízo à saúde psicológica e à autodeterminação (BRASIL, 2006, s/p.).

De acordo com Machado (2013), foi a partir da referida lei que entrou no cenário jurídico legal uma definição de violência psicológica com tamanha completude e complexidade, abrindo possibilidades estratégicas de concretização do dano, sem, no entanto, esgotá-las nesse enunciado. A violência psicológica foi introduzida na Lei Maria da Penha justamente para que a violência doméstica não ficasse atrelada unicamente a um corpo físico, mas que abrangesse, também e majoritariamente, a visão de um corpo psicofísico dessas mulheres (MACHADO, 2013 apud MACHADO; DEZANOSKI, 2014).

Como consequências para a saúde emocional e mental, causados pela violência psicológica sofrida pela mulher, Ferreira (2012) e Rodrigues (2014) pontuam vários agravos, como: isolamento social, vergonha, culpa, medo de represálias, isolamento emocional, desconfiança, ansiedade, depressão, transtorno de estresse póstraumático, transtornos no sono, na alimentação, baixa autoestima, pensamentos suicidas e tentativas de suicídio, com êxito ou não. Apesar da invisibilidade dos danos sofridos, isto pode deixar sequelas bem visíveis, como processos de somatização e interferência na construção da identidade e subjetividade. Pode-se dizer, contudo, que a violência psicológica contra a mulher é a forma mais cruel delas, porque, além de deixar sequelas irremediáveis, pode durar até mesmo toda a vida, invadindo os limites do bem-estar, causando pânico e provocando danos mentais que podem anular e destruir a personalidade de uma pessoa.

\section{Aspectos legais do combate à violência psicológica contra a mulher}

A elaboração e aprovação da lei Maria da Penha são marcadas por um processo de construção coletiva, que envolveu diversos atores sociais e políticos e contou com a colaboração de organizações não governamentais (ONGs), movimentos feministas e a participação dos poderes executivo e legislativo, no âmbito federal (FERNANDES, 2012). Assim, cabe detalhar a evolução histórica deste processo, destacando a luta e a reivindicação dos movimentos feministas quanto ao direito das mulheres, na década de 1970. Destaca-se, também nesse período, a 
mobilização contra o assassinato de mulheres, justificados por um ato de amor ou ainda pela "tese da legítima defesa da honra", argumento advindo da legislação colonial e que se perpetuava nas decisões do júri popular (THOMAS, 1995; BARSTED; HERMANN, 1995, apud BARSTED, 2011).

Seguindo em luta, a década de 1990 se manteve com pauta política relacionada à ampliação dessas delegacias especializadas e da criação de outros serviços no intuito de combater à violência com mais efetividade, como a instituição de abrigos e centros de referências (BARSTED, 2011). Também neste período, surgiram manifestações com interesse para que a violência doméstica fosse tratada como um problema de saúde pública e, para tanto, reivindicaram que o Programa de Assistência Integral de Saúde a Mulher (PAISM) - criado em 1983 abarcasse a mesma, visto que tal violência gera tanto danos médicos como psíquicos, assim como outros agravos que fazem parte da integralidade contextual, independente de classe econômica, étnica ou posição social (TAVARES, 2000).

A violência contra a figura feminina, além de uma questão criminal, precisava ser vista como uma questão de saúde, já que, sem o amparo devido do Sistema de Saúde, as mulheres eram submetidas aos documentos necessários para se comprovar uma agressão, como boletins de ocorrência, termo circunstanciado, laudo de corpo e delito, dentre outros, passando a vítima a ter papel secundário e sua saúde, em nenhum momento, levada em conta. Em 2006, sob a Lei $\mathrm{n}^{\circ} 11.340$, entrou no cenário jurídico-legal brasileiro a Lei Maria da Penha, assim denominada em homenagem a uma de suas vítimas, Maria da Penha Maia Fernandes, que vivenciou, durante 20 anos, agressões constantes e duas tentativas de assassinato por parte do seu, até então marido, trazendo-lhe como uma das consequências a sua paraplegia (RODRIGUES, 2014).

Tratando-se da violência psicológica, Machado (2013) destaca que no ano de 1997, a criação da Lei da Tortura ( ${ }^{\circ}$ 9.455/97) trouxe à tona o conceito de violência psicológica, que mesmo não sendo tratado em lei específica para caso de violência doméstica, mobilizou a discussão sobre danos e sofrimento psíquico e foi visto como um documento significativo, também, para a elaboração do texto da Lei Maria da Penha. Gonçalves e Cruz (2006) citam a conceituação da violência psicológica pela Lei Maria da Penha como um grande avanço, já que nenhuma legislação, até então, a tipificava. Já Machado (2013), coloca que na Lei 
Maria da Penha não se encontra tipos penais, mas, sim, condutas que exemplificam ou descrevem, sem sanções atribuídas, modalidades de violências domésticas contra mulheres, incluindo a psicológica. Dito isto, no que tange a percepção jurídica da violência psicológica, encontra-se dificuldade na própria tipificação penal da mesma, pois, dando prosseguimento à própria linha de raciocínio da autora supracitada, não existe na aplicação da lei um dispositivo que admita a proteção da saúde psicológica/psíquica, estando as possibilidades circunscritas, dentro do Código Penal, como formas de ameaça (art.147), injúria (art.140) e constrangimento ilegal (art.146). Assim, diante desta complexidade conceitual da violência psicológica, referida na Lei Maria da Penha, evidencia-se a dificuldade de uma intervenção criminal, tendo condutas que já estavam penalmente descritas se contrapondo com outras que não são passíveis de criminalização (MACHADO, 2013).

Dessa forma, observa-se o quão é importante a postura adotada pelo Ministério Público, especificamente em relação à opinião dos promotores(as) de Justiça, que podem barrar os fluxos de violência psicológica já na porta de entrada do sistema judiciário. Barsted e Pitanguy (2013) entendem a "[...] constatação de que as mulheres no Brasil ainda enfrentam um déficit em termos de reconhecimento social do seu pleno direito à Justiça e que interfere com as práticas discriminatórias que prevalecem nas instituições policiais e judiciais" (p. 6). Tal dado nos mostra a dificuldade que as mulheres têm de exercer seu papel dentro da sociedade brasileira, mesmo dispondo de dispositivos direcionados a elas. Discutir sobre a percepção do conceito de violência psicológica e das múltiplas formas em que ela se apresenta se pretende "sensibilizar os operadores de direito caracterizando a problemática e mostrando a necessidade de se lidar com o assunto de forma bastante sensível" (PEREIRA, 2006, p.5.).

\section{Perfil da Invisibilidade: surpresa ou constatação?}

Com a participação de 46 pessoas, (31 mulheres e 15 homens), o que destacou a participação das mulheres com número significativamente maior, representando mais que o dobro de homens, o questionário foi formado por 15 perguntas, das quais as três primeiras foram introdutórias e realizadas com o objetivo de filtrar as respostas de acordo com o sexo, a instituição de ensino e o período. Entre as 
instituições, a maioria das opiniões vieram dos estudantes da Universidade Federal De Alagoas - UFAL (n. 24), seguido do Centro Universitário Tiradentes - UNIT (n. 14), Associação Caruarense De Ensino Superior E Técnico - ASCES (n. 4) e empatados Centro De Estudos Superiores De Maceió - CESMAC e Sociedade De Ensino Universitário Do Nordeste - SEUNE (n. 2), das quais 14 pessoas cursam o $10^{\circ}$ período, 10 pessoas cursam o $9^{\circ}$, nove cursam o $7^{\circ}$, sete, o $5^{\circ}$ e quatro pessoas, o $2^{\circ}$ período. Ainda teve uma pessoa que respondeu que já estava formada e outra que apenas colocou "Direito" ao invés de informar o período.

Em análise, obteve-se concordância de todos os participantes sobre a criação da Lei Maria da Penha como ordenamento jurídico favorável às mulheres e a necessidade das mulheres violentadas (por qualquer tipo de violência) denunciarem seus agressores. Sobre o posicionamento diante do acolhimento de uma denúncia obteve pelo menos uma escolha em cada alternativa - inclusive, um homem discordou totalmente. Sobre a abordagem direcionados a comportamentos do dia a dia, que muitas vezes podem passar despercebidos, mas merecem atenção e, principalmente, reflexão, 28,57\% concordaram parcialmente que há um exagero na classificação de determinados comportamentos como violência psicológica. Diante da afirmativa "Em brigas de casais não devemos nos intrometer" a maioria discordou, demonstrando uma maior conscientização em cima das sérias consequências que envolvem uma omissão nas relações violentas. Apenas dois participante discordaram que o ciúme não serve de referência para o gostar do outro e que o fato de não compartilhar senhas não significa que se tem algo para esconder. Acerca do comportamento das mulheres comprometidas serem avaliados com muito mais rigor do que os de homens comprometidos, 31 participantes concordaram totalmente e 12 concordaram parcialmente, sinalizando o quanto o comportamento machista ainda está presente na nossa sociedade.

Analisou-se também quantas pessoas conhecem ou não alguma mulher vítima de violência, tendo 37 respostas afirmativas e 9 negativas. Sobre o tipo de violência que essas mulheres conhecidas sofreram e os resultados constataram a violência psicológica como a mais frequente $(69,57 \%)$ seguida de um percentual bem próximo da violência física $(60,87 \%)$ e, em um número mais baixo, a sexual (23,91\%), mas teve também quem especificou outros tipos de violência como a moral e a patrimonial ou quem não soube informar (17,39\%). Na mesma linha, 
investigou-se quantos dos entrevistados já sofreram violência e constatou-se que homens e mulheres já sofreram violência psicológica, em um percentual de 33,33\% e 46,67\%, respectivamente. Sobre a percepção de gravidade das violências pôde-se perceber uma unanimidade entre homens e mulheres na indicação da maior gravidade para a violência sexual, seguida da física, psicológica e moral, respectivamente.

Quando questionados sobre comportamento que definem violência psicológica, as respostas dos homens foram: ameaça; rebaixamento da mulher; chantagem; comportamentos que alterem a noção da mulher sobre certo e errado relacionada a si mesma; humilhação; ferir a autoestima; comportamento agressivo de modo manipulador que provoque danos psicológicos graves; submissão; xingamentos; controle das ações; pensamentos; desejos; stalkear; perseguição; fiscalização do dia-a-dia; usar palavras de baixo calão; $e$ coação moral. Para as mulheres: chantagem emocional; xingamentos; menosprezo; desvalorização da mulher; proibição; ameaça; rebaixamento; atitudes que levem o outro a ter medo; ditar regras de comportamento baseado em gênero se apresenta junto com outros tipos de violência, como física e sexual; interiorização; agressão verbal; gestos ou ações que diminuam a autoestima e autoimagem da mulher; ciúme excessivo e doentio; perseguição; falta de empatia; manipulação; tratamento abusivo; exploração emocional; insultar $e$ rebaixar a mulher até que ela acredite que é inferior; ameaçar praticar violência sexual ou física; ameaça de morte; ameaça aos filhos; ridicularização que provoque isolamento; usar palavras para tratar a mulher como inferior; pressões psicológicas; manipular sentimentos; provocar sentimento de inutilidade; injúria; denegrir a imagem da mulher; e intimidação. Percebe-se que ambas as descrições apresentam elementos iguais, porém, as mulheres conseguiram descrever com mais detalhes os comportamentos do que acreditam ser violência psicológica. Cabe destacar que em algumas respostas, as mulheres já correlacionavam violência psicológica com outros tipos de violências, conforme é descrita pela literatura. De maneira geral, as respostas foram coerentes e estão de acordo com a definição de violência psicológica descrita na Lei Maria da Penha.

Sobre a formação acadêmica, percebe-se que ainda há um déficit, a maioria (33 pessoas) afirma ter sentido a necessidade de aprofundar o conhecimento sobre a Lei Maria da Penha. De maneira geral, os 
entrevistados não tem conhecimento total sobre as nuances da Lei Maria da Penha, demonstrado pelo desconhecimento de não haver necessidade de vínculo familiar ou coabitação para proceder com a denúncia e pena alternativa. Quando instigados a tipificar a violência psicológica, das 46 pessoas entrevistas, 12 não souberam responder a esta questão. Os demais tipificaram como: todo ato ou fala que agrida fisicamente ou não; crime, como violência doméstica e familiar citando o artigo $7^{\circ}$ da Lei Maria da Penha; abuso emocional; dano psíquico recorrente; crime de ação civil pública; ameaças; ações que tragam transtorno de ordem psicológica; violência que atinge o desenvolvimento psicossocial do ser humano; e devido à falta de estudo com relação a Lei Maria da Penha em minha graduação, não sei tipificar a violência psicológica separadamente, mas como eu acho que ela sempre vem atrelada à iminência de uma violência física, inclusive, deixando a maioria das pessoas para denunciar quando esta última acontecer, tipificaria como tal (violência física). Muitos responderam a questão colocando comportamentos característicos desta violência, mas não a tipificação. Tal dado é sinalizador para duas questões: 1) O texto da Lei Maria da Penha não deixa claro como tipificar tal violência; 2) A formação deixa a desejar neste quesito, necessitando ser mais pesquisado e aprofundado. Sobre como proceder diante de uma denúncia de violência psicológica, mesmo não tendo certeza de como proceder à maioria respondeu que a acolheria. Alguns por não terem conhecimento sobre tal violência disseram que encaminhariam para órgãos como o Centro de Referência da Mulher, Delegacia da Mulher, Assistência Social e para tratamento e avaliação psicológica. Tal dado pode sinalizar uma abertura para um trabalho interdisciplinar, com o intuito de atender a demanda da melhor forma possível e aplicar a Lei de forma justa.

\section{Considerações Finais}

Apesar do termo 'violência psicológica' estar sendo mais utilizado e comentado, lidar com este tipo violência ainda é um desafio, haja vista que muitos dos seus comportamentos já estão bastante naturalizados e a própria Lei Maria da Penha não deixa claro como acolher, encaminhar e tipificar a demanda, ficando a critério de quem julga a questão. A própria não deixa claro como acolher, encaminhar e tipificar a demanda, deixando a critério de quem julga a questão. Mesmo diante da notoriedade que a violência psicológica vem adquirindo, não basta 
explicar o significado deste tipo de violência, se não houver um aparato mais claro e objetivo de como proceder e quais outros profissionais recorrer, caso necessário, como psicólogos e assistentes sociais, devendo, portanto, à psicologia aproveitar esta necessidade para efetivar trabalhos interdisciplinares e pesquisas que promovam mais esta discussão.

Comparando-se as respostas de acordo com a Instituição de Ensino Superior, percebemos que da IES UNIT apenas mulheres responderam ao questionário e nas demais houve uma mescla entre homens e mulheres, porém, sempre sendo maior o número de mulheres. Quanto ao estudo da Lei Maria da Penha na academia, as alunas da UNIT estudaram de maneira mais satisfatória que as demais IES. Apesar da insatisfação apontada, boa parte dos alunos conseguiu responder as demais questões referentes à Lei, levantando a hipótese de que realmente há uma procura extracurricular da temática por algumas pessoas. Não há efetiva diferença nas respostas de acordo com a IES, mas, sim, de acordo com o sexo. As mulheres conseguiram dar respostas mais claras, detalhadas e assertivas quando comparadas às respostas dos homens. Assim, a diferença em relação ao sexo nos traz a preocupação se apenas as mulheres - mais afiadas com a temática nesta pesquisa ficarão com a responsabilidade de proceder de forma coerente uma denúncia de violência psicológica, posto que o parecer final depende da autoridade que julga e de sua percepção individual da situação. Então, como quebrar este ciclo sem a ajuda dos homens? Acredita-se que seja difícil sem a ajuda deles, mesmo porque o universo do Direito é predominantemente masculino, machista e patriarcal. Por isso, faz-se necessário uma conscientização, para ambos os sexos, no que se refere à violência psicológica, esclarecendo como ela funciona, suas características e sintomas e de que forma pode-se proceder, cabendo à própria psicologia, diante da relevância do tema, oferecer um olhar diferenciado para o mesmo, a fim de favorecer a desconstrução da naturalização que muitos comportamentos tidos como violência psicológica possuem.

\section{Referências}

BARSTED, L. L; PITANGUY, J. Violência Contra a Mulher e Acesso à Justiça. Estudo comparativo sobre a aplicação da Lei Maria da Penha em cinco capitais. Relatório final. 2013. Disponível em: < 
http:www.cepia.org.br/pesquisa_out. pdf.>. Acesso em: 02 de Nov de 2015 .

BARSTED, L. Lei Maria da Penha: uma experiência bem sucedida de advocacy feminista. In: CAMPOS, C. H. (Org.). Lei Maria da Penha Comentada em uma perspectiva jurídico-feminista. Rio de Janeiro: Editora Lúmen Juris, 2011. P. 13-38. Disponível em: < http:// www.compromissoeatitude.org.br>. Acesso em: 26 abr. 2016.

BRASIL. LEI MARIA DA PENHA. Lei No 11.340, de 7 de Agosto de 2006. Presidência da República. Casa Civil. Disponível em <http:// www.planalto.gov.br/ccivil_o3/_Ato2004-2006/2006/Lei/ L11340.htm> Acesso em: 19 de Out. 2015.

CAMPOS, C. H. Razão e Sensibilidade: Teoria Feminista do Direito e Lei Maria da Penha. In: .(Org.). Lei Maria da Penha Comentada em uma perspectiva jurídico-feminista. Rio de Janeiro: Editora Lumen Juris, 2011. P. 1-12. Disponível em: <http:// www.compromissoeatitude.org.br>. Acesso em: 26 abr. 2016.

DATA SENADO. Violência doméstica e familiar contra a mulher. Secretaria de transparência. Março, 2013. Disponível em: < http:// www.senado.gov.br/senado/datasenado/pdf/datasenado/DataSenadoPesquisa-Violencia_Domestica_contra_a_Mulher_2013.pdf $>$. Acesso em: 16 ago. 2015.

FERREIRA, W. (In)visíveis sequelas: A violência psicológica contra a mulher sob o enfoque gestáltico. Universidade Federal do Pará. Instituto de Filosofia e Ciência Humanas. Programa de pósgraduação em Psicologia. Belém - Pará: 2010. Disponível em: <http:// www.ppgp.ufpa.br/dissert/Wanderlea.pdf > . Acesso em: 02 nov. 2015.

GONÇALVES, A; CRUZ, A. A implementação da Lei 11.340 Maria da Penha. In: PEREIRA, M. A. E (coord.).- Protegendo as Mulheres da Violência Doméstica. Seminário de capacitação para Juízes, procuradores, promotores, advogados e delegados no Brasil. Brasília/DF, 2006. Disponível em: < http://midia.pgr.mpf.gov.br/.../ diadamulher/docs/cartilha_violencia_doméstica.pdf.>. Acesso em: 02 nov. 2015 .

LIMA, D. C; BÜCHELE, F; CLÍMACO, D. A. Homens, Gênero e Violência contra a Mulher. Saúde Soc., São Paulo, v.17, n-2, p. 69-81, 2008. 
Disponível em: <het.//: scholar.google.com.br>. Acesso em: 06 de set de 2015.

MACHADO, I. V, DEZANOSKI, M. Exploração Do Conceito De Violência Psicológica Na Lei 11.340/o6. Revista Gênero \& Direito (1) 2014. Disponível em: < http://periodicos.ufpb.br/ojs/index.php/ged/article/ view/18063/10568>. Acesso em: 19 out. 2015.

MACHADO, I. V. Da dor no corpo à dor na alma [tese]: uma leitura do conceito de violência psicológica da Lei Maria da Penha. Prêmio CAPES de Tese. Florianópolis, SC. UFSC: 2013. 283 p. Disponível em: <http://pct.capes.gov.br/teses/2013/41001010037Po/TES.PDF >. Acesso em: 16 ago. 2015.

MEDRADO, B; MÉLLO, R. P. Posicionamentos Críticos e Éticos sobre a violência contra as mulheres. Psicologia \& Sociedade; 20, Edição Especial: 78-86, 2008. Disponível em: <http://scholar.google.com.br>. Acesso em: 25 de Set. 2015.

MUSZKAT S. Violência e masculinidade: uma contribuição psicanalítica aos estudos das relações de gênero[dissertação]. São Paulo: Universidade de São Paulo; 2006. Disponível em: <http:// www.teses.usp.br/teses/disponíveis/47/47134/tde-26092006091251/ $>$ Acesso em 19 Out. 2015.

PEREIRA, M. A. E.- Protegendo as Mulheres da Violência Doméstica. Seminário de capacitação para Juízes, procuradores, promotores, advogados e delegados no Brasil. Brasília/DF, 2006. Disponível em: < http://midia.pgr.mpf.gov.br/.../diadamulher/docs/ cartilha_violencia_doméstica.pdf.>. Acesso em: 02 nov. 2015.

RODRIGUES, R. B. Violência contra mulheres: Homicídios no Município de Belém. Universidade Federal do Pará. Universidade Federal do Amazonas. Fundação Oswaldo Cruz. Centro de Pesquisa Leônidas \& Maria Deane. Mestrado multidisciplinar em saúde, sociedade e endemias na Amazônia. Belém, 2014. Disponível em: < http://tede.ufam.edu.br/bitstream/tede/4625/2/

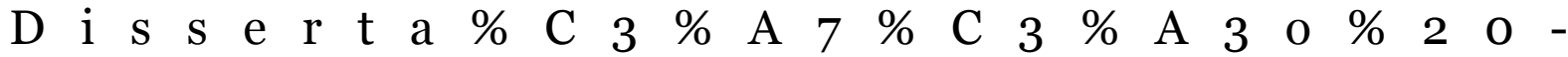
\%20Roselene\%2oBatista\%2oRodrigues.pdf>. Acesso em: 02 nov. 2015.

SACRAMENTO, Lívia de Tartari e; REZENDE, Manuel Morgado. Violências: lembrando alguns conceitos. Aletheia, Canoas, n. 24, dez. 
2006. Disponível em <http://pepsic.bvsalud.org/scielo.php? script $=$ sci_arttext\&pid $=$ S1413-03942006000300009\&lng $=$ pt\&nrm $=$ iso >. Acesso em: 27 set. 2015 .

TAVARES, D. M. C. Violência doméstica: uma questão de saúde pública. USP - Faculdade de Saúde Pública. Dissertação de Mestrado. São Paulo: 2000. Disponível em: < http://www.teses.usp.br/teses/ disponiveis/6/6135/tde-29082014-161000/en.php>. Acesso em: 02 nov. 2015 . 


\title{
Psychological Violence Against Women: Acknowledgment and Visibility
}

\begin{abstract}
According to Data Senate (2013), about 38\% of women claim to have been target of psychological violence in Brazil. Therefore, this work aims to discuss how Law students perceive psychological violence against women, analyzing how they are being prepared to deal with this work demand and whether those students and future professionals are able to acknowledge psychological violence as a precursor of other forms of violence. We made use of an online survey about the perception of types of violence and juridical notions over the Maria da Penha Law, which was used as a theoretical framework for discussion. Results show that even though this theme have grown in importance a large number of students weren't able to typify psychological violence. It is noted that explaining the meaning of this form of violence is not enough if there is no clear and objective juridical apparatus on how to proceed and on what kind of professionals to call upon. It is up to Psychology to promote interdisciplinary actions in order to stimulate such discussion and creating the possibility to build new spaces of discussion and implementation of an integrated network of knowledge to support women targeted by violence, and to discuss the juridical typification of psychological violence.
\end{abstract}

KEYWords: Psychological violence, invisibility, Maria da Penha Law.

Gabriela Bothrel ECHEVERRIA

Graduada em Psicologia pelo Centro Universitário Tiradentes (UNIT). Atualmente Mestranda do Programa de Pós-graduação em Sociedade, Tecnologias e Políticas Públicas pelo Centro Universitário Tiradentes (UNIT). Especializanda em Educação em Gênero e Direitos Humanos pela Universidade Federal da Bahia

(UFBA). 